\title{
Mathematical Model and Analysis of the Z-Source Inverter
}

\author{
Lina J. Rashad ${ }^{1}$
}

\begin{abstract}
Model and analysis of Z-Source Inverter is the dominant aspect to investigate the performance of the $Z$ Source Inverter. This paper presents a comprehensive analysis of the Z-Source Inverter model by the aid of mathematical analytical approach. AC small signal perturbations are derived based on state space averaging model and state variables are linearization at equilibrium (steady state values). The AC small signal model is analyzed to study the changes that occur in the behavior of ZSI such as change the input voltage, the current that pass through the load, or the shoot-through duty cycle. Moreover, the mathematical model gives the ability of choosing the optimal values of the capacitance and inductance of the $Z$ source network. The analytical results are verified by comparing them with that of the actual ZSI switching circuit analysis method. The comparison shows significant convergence between the presented analytical method and the actual ZSI analysis method. The percentage errors between the two methods, for both of the state variables (inductance current and capacitance voltage) in the ZSI, are very acceptable for major analysis requirements. The presented model can replace the actual ZSI switching circuit model in an efficient manner in terms of the accuracy of the results.

Index Terms-Z-Source Inverter, Mathematical analysis, State space averaging model, AC small signal model Inductance current and capacitance voltage.
\end{abstract}

\section{INTRODUCTION}

Mathematical model is very important to study the changes that occur in the behavior of ZSI such as change the input voltage, the current that pass through the load, or the shoot-through duty cycle. Moreover, the mathematical model gives the ability of choosing the optimal values of the capacitance and inductance of the Z-source network. Models in engineering are generally comprise important behaviors in a system but in the other hand it is neglect the effect of the second order response. Precision and decreasing the complexity of model are needed and these two adjectives are proportional related and rely on the level of the assumptions that made by the designer. Engineering models that used for power inverter can be represented by different techniques and different levels of precision and complexity [1].

The general implementation of Z-source network is depicted in Fig. 1. This inverter can also be used at AC-toDC and AC-to-AC converter systems. ZSI has a unique impedance as the X-shape which is consist of two split symmetrical inductances and capacitances to link between input DC source voltage and the DC/AC power conversion bridge [2]. The ZSI can operate as a buck-boost operation which gives any desired output voltage from any value of

\footnotetext{
${ }^{1}$ Published on January 25, 2020.

Lina J. Rashad, University of Technology Baghdad, Iraq.

(e-mail: 30082@uotechnology.edu.iq)
}

the input voltage sources. This can be achieved by an additional switching state which is called the shoot-through state that does not exist in VSI and CSI.

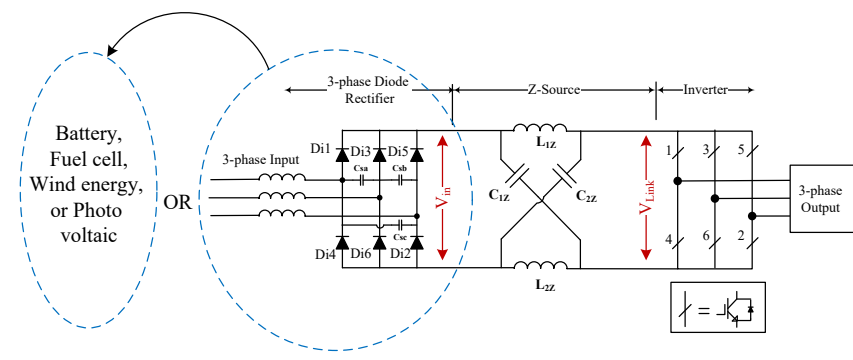

Fig. 1. General implementation of Z-source network

A simple model is needed for energy conversion that depends on the assumptions and approximations. For example, at high frequencies there are parasitic resistive effects that occur in series with capacitances and inductances of ZSI. These effects can be represented by equivalent series resistance $\mathrm{rl}$ that exist in series with capacitance and by equivalent series resistance $\mathrm{r} 2$ exist in series with inductance. If the model of inverter neither uses r1 nor $\mathrm{r} 2$, this will decrease the complexity and will not guess any dynamics behavior caused by $\mathrm{r} 1$ and $\mathrm{r} 2$ [3].

Most assumptions that made by the designer in modeling are neglecting the switching ripple and neglecting $\mathrm{r} 1$ and $\mathrm{r} 2$. Different techniques of modeling in energy conversion are used in power electronic. These techniques are circuit average model technique and state space averaging model technique. If assume ideal elements, the form of the end result of these methods is different from each other but they have the same model. In this chapter, AC small signal perturbations are derived based on state space averaging model and state variables are linearization at equilibrium (steady state values) [4]-[6].

\section{Z-SOURCE INVERTER}

In 2002, Fung Zheng Peng proposed a new type of power conversion which is called Z-source inverter [7]. Fig. 2 shows the general shape of a ZSI implemented as a threephase inverter. This inverter is applied to DC-to-AC and AC-to-AC energy conversion but the most application that used in ZSI is DC-to-AC power conversion. ZSI can overcome the limitations and theoretical barriers of the traditional inverters.

ZSI is consist of two symmetrical inductance $\mathrm{L}_{12}$ and $\mathrm{L}_{2 Z}$ and two capacitance $\mathrm{C}_{1 Z}$ and $\mathrm{C}_{2 Z}$ that connected as an $\mathrm{X}$-shape, this $\mathrm{X}$-shape represents an impedance source for ZSI that connected between the DC input voltage source and inverter bridge. The DC input voltage source can be a fuel cell stack, battery, thyristor or diode rectifier. The switches that used in the inverter bridge are combined with the diodes 
as an anti-parallel combination [7]. ZSI has an additional switching state beside the eight switching states that exist in the traditional inverter (VSI and CSI) which is called shootthrough state that distributed in equal amounts of time inside the zero (null) states in the switching pattern of the ZSI while the active states stay unchanged [8].

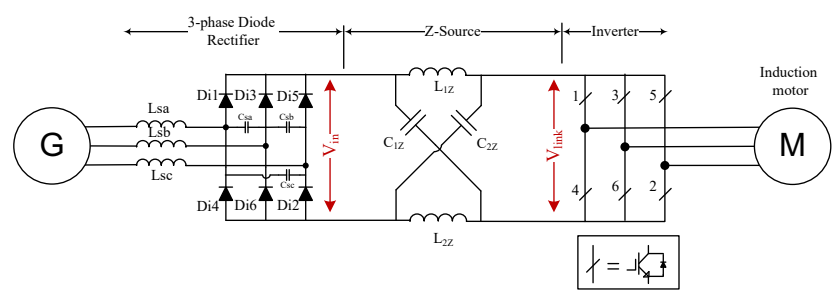

Fig. 2. General three-phase Z-source inverter

\section{ThE PRINCIPLE Operation AND CONTROL OF ZSI}

The Z-network connected between the three-phase diode bridge rectifier, which represents a DC voltage source, and the three-phase inverter bridge. The input DC voltage source consists of a three-phase voltage with a three-phase diode rectifier with input capacitance $\left(\mathrm{C}_{\mathrm{sa}}, \mathrm{C}_{\mathrm{sb}}\right.$ and $\left.\mathrm{C}_{\mathrm{sc}}\right)$ which are connected between the three-phase legs in the rectifier bridge, and feeding the ZSI as a DC voltage source [9]. The purpose of the input capacitance is to repress voltage surge that occurs by the line inductance $\left(\mathrm{L}_{\mathrm{sa}}, \mathrm{L}_{\mathrm{sb}}, \mathrm{L}_{\mathrm{sc}}\right)$ during shoot-through mode (diode commutation) of the three-phase inverter, so the requiring value of the input capacitance is small. At any time only two phase legs may conduct when these two legs have the highest potential difference, then a current flow from the input $\mathrm{AC}$ line to the $\mathrm{DC}$ voltage side. The two diodes $\left(\mathrm{D}_{\mathrm{i} 1}, \mathrm{D}_{\mathrm{i} 3}\right.$ or $\mathrm{D}_{\mathrm{i} 5}$ and $\mathrm{D}_{\mathrm{i} 4}, \mathrm{D}_{\mathrm{i} 6}$, or $\left.\mathrm{D}_{\mathrm{i} 2}\right)$ may conduct in series by the input capacitance $\left(\mathrm{C}_{\mathrm{sa}}, \mathrm{C}_{\mathrm{sb}}\right.$ or $\left.\mathrm{C}_{\mathrm{sc}}\right)$ respectively as seen from the ZSI as depicted in Fig. 3 [9].

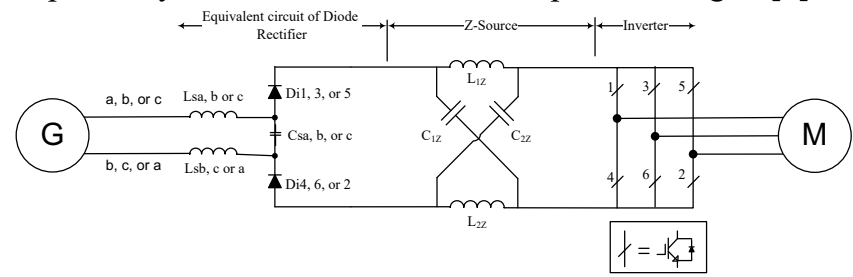

Fig. 3 Equivalent circuit of the rectifier bridge as seen from the Z-source network.

For example, at the first half cycle the two diodes $\mathrm{D}_{\mathrm{i} 3}$ and $\mathrm{D}_{\mathrm{i} 2}$ are conduct with capacitance $\mathrm{C}_{\mathrm{sb}}$ as seen from the ZSI, the diode bridge with the capacitance $\mathrm{C}_{\text {sa }}$ can be formed a DC input voltage source connected in series with two diodes as depicted in Fig. 4. These two diodes acting like one leg when they conduct in series as seen from the ZSI.

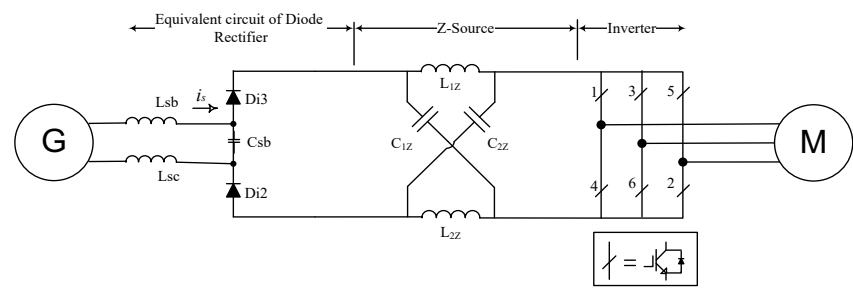

Fig. 4. Effect of the capacitance $\mathrm{C}_{\mathrm{sb}}$ as seen from the ZSI
The equivalent circuit in Fig. 2 has three operation modes that depending on the nine switching states of the three-phase inverter bridge [9].

\section{A. Mode-1 (active state):}

This mode occurs when the three-phase inverter bridge is operating in one of the six conventional active states, so this inverter bridge acting as input current source (is) that seen from the circuit of ZSI. Fig. 5 depicts the circuit of mode-1. ZSI evermore forces Di3 and Di2 to conduct and to pass a current amount equal to $2 \mathrm{I}_{\mathrm{LZ}}-\mathrm{I}_{\mathrm{O}}$ where $\mathrm{I}_{\mathrm{LZ}}$ is the inductance current and Io is the inverter current. The current value of the inductance $\mathrm{L}_{1 z}$ is identical to the current value of the inductance $\mathrm{L}_{2 Z}$ because $\mathrm{L}_{1 Z}=\mathrm{L}_{2 Z}$. This unique characteristic can reduce input harmonic current because it widens the line current conducting intervals.

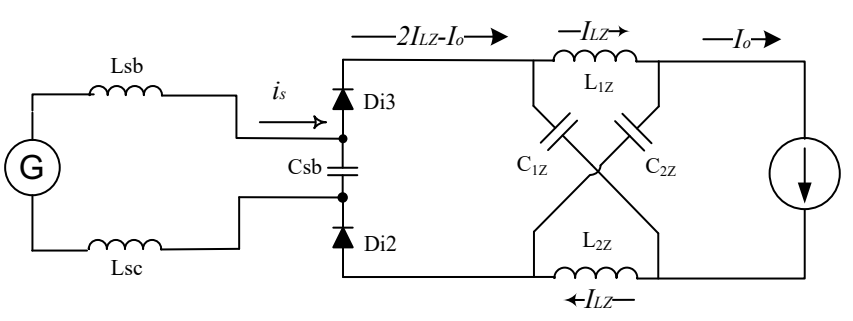

Fig. 5. The circuit of mode-1

\section{B. Mode-2 (non-active state)}

This mode occurs when the three-phase inverter bridge is operating in one of the two zero vectors (or null states), then the equivalent circuit of ZSI acting as an open circuit that seen from ZSI. Again the diodes (Di3 and Di2) conduct and carry the inductance currents as shown in Fig. 6, this conductor current contributes to reduce harmonic of line current [9].

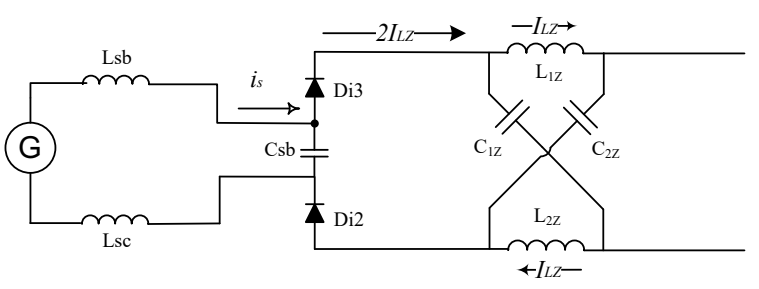

Fig. 6. The circuit of mode-2

\section{Mode-3 (shoot-through state):}

This mode occurs when the three-phase inverter bridge is operating in one of the seven shoot-through switching states. During mode-3, diodes (Di3 and Di2) are off disconnecting the input DC link from the AC output line, and then the line current is flows to the input capacitance $\mathrm{C}_{\mathrm{sb}}$ as shown in Fig. 7. The shootthrough time $\mathrm{T}_{\mathrm{sh}}$ or its duty ratio $\left(\mathrm{T}_{\mathrm{sh}} / \mathrm{T}_{\mathrm{s}}\right)$ must be determined for boosting the output voltage [9]. 


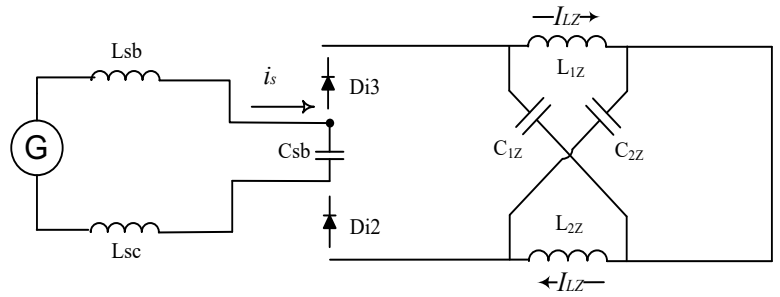

Fig. 7. The circuit of mode-3

All relationships that obtained from the three operating modes are summarized as [10]:

$$
\begin{aligned}
& V_{c 1 z}=V_{c 2 z}=V_{c z}=\frac{1-\frac{T_{s h}}{T s}}{1-2 \frac{T_{s h}}{T s}}=\frac{B_{f}+1}{2} V_{i n} \\
& \widehat{V}_{a c}=M_{i} B_{f} \frac{V_{\text {in }}}{2} \\
& V_{\text {in }}=\frac{2}{\pi} \sqrt{2} V_{r m s} \\
& B_{f}=\frac{1}{1-2 \frac{T_{s h}}{T_{s}}} \\
& V_{\text {Link }}=B_{f} V_{\text {in }}=\frac{2 B_{f}}{B_{f}+1} V_{c z}
\end{aligned}
$$

The stress voltage across the switching devices of the three-phase inverter is:

$$
V_{\text {stress }}=\frac{1}{1-2 D_{\text {sh }}} V_{\text {in }}
$$

Where: $V_{c 1 z}, V_{c 2 z}$ : The voltages of the capacitance $C_{c 1 z}$ and $C_{c 2 z}$ and these capacitance have the same value since the X-shape of ZSI is symmetrical.

$\mathrm{T}_{\mathrm{sh}}$ : The shoot-through time interval over one switching time Ts.

$\widehat{V}_{a c}$ : The output peak phase voltage that produced by the three-phase inverter.

$B_{f}:$ The boosting factor.

$M_{i}$ : The modulation index.

$V_{\text {in }}$ : The value of the input dc voltage that applied to the ZSI.

$V_{\text {Link }}$ : The value of the equivalent DC-link voltage that applied to the three-phase inverter bridge.

$\mathrm{D}_{\text {sh }}$ : is the shoot through duty ratio.

\section{STATE SPACE AVERAGING METHOD}

This method is mostly used in modeling of energy conversion. It's a statutory form so as to write the differential equations for describing a system. The storage of energy produced by the dependent currents, which pass through the inductance, and the dependent voltages across the capacitance are the physical state variables for a system [1]. To find the value of state variables at any time, it must return to the previous values of the system. When the values of all state variables are known at time to and the inputs are known at time equal or greater than to then the differential equation can be solved at any time.

Equation (7) represents the state space equation of a system:

$$
\left.\begin{array}{rl}
\mathrm{K} \nabla \mathrm{x}(\mathrm{t}) & =\mathrm{ax}(\mathrm{t})+\mathrm{bu}(\mathrm{t}) \\
\mathrm{y}(\mathrm{t}) & =\mathrm{cx}(\mathrm{t})+\mathrm{eu}(\mathrm{t})
\end{array}\right\}
$$

Where $x(t)$ is the state vector that contains the state variables (the currents that pass through the inductance and the voltages across the capacitance), $\mathrm{u}(\mathrm{t})$ is the input vector that contains independent inputs to the system, for example the input voltage source, $\mathrm{K}$ contains the values of inductance and capacitance as a matrix, $K \nabla x(t)$ is a vector of the currents that pass through the inductance and the voltages across the capacitance, which are represent a linear combinations of the element of the $\mathrm{x}(\mathrm{t})$ and $\mathrm{u}(\mathrm{t})$, the matrices ' $a$ ' and ' $b$ ' are constant of proportionality. Also, the output vector $\mathrm{y}(\mathrm{t})$ can be obtained by linear combination with the elements of $x(t)$ and $u(t)$. The matrix ' $c$ ' and matrix 'e' are also constant of proportionality [5].

A switching period Ts for energy conversion can be divided to two subintervals. The state space equations of the converter at the first subinterval $(0 \leq \mathrm{t} \leq \mathrm{Tsh})$ are:

$$
\left.\begin{array}{rl}
\mathrm{K} \nabla \mathrm{x}(\mathrm{t}) & =\mathrm{a}_{1} \mathrm{x}(\mathrm{t})+\mathrm{b}_{1} \mathrm{u}(\mathrm{t}) \\
\mathrm{y}(\mathrm{t}) & =\mathrm{c}_{1} \mathrm{x}(\mathrm{t})+\mathrm{e}_{1} \mathrm{u}(\mathrm{t})
\end{array}\right\}
$$

And also by the same way, the state space equations for the second subinterval $(\mathrm{Tsh} \leq \mathrm{t} \leq \mathrm{Ts})$ are:

$$
\left.\begin{array}{rl}
\mathrm{K} \nabla \mathrm{x}(\mathrm{t}) & =\mathrm{a}_{2} \mathrm{x}(\mathrm{t})+\mathrm{b}_{2} \mathrm{u}(\mathrm{t}) \\
\mathrm{y}(\mathrm{t}) & =\mathrm{c}_{2} \mathrm{x}(\mathrm{t})+\mathrm{e}_{2} \mathrm{u}(\mathrm{t})
\end{array}\right\}
$$

The two equations above evolve the state space model of the energy conversion. When the state space method are used, the model of this converter can be averaged the switching period provided that the switching frequency $f_{s z}$ of the converter is much higher than the natural frequency $f_{n}$.

The procedure gives the averaging state space model and the steady state equation of the AC small signal model. The equations of averaging state space model that describe the converter in steady state:

$$
\left.\begin{array}{l}
0=a X+b U \\
Y=c X+e U
\end{array}\right\}
$$

The matrices of the averaged model are:

$$
\left.\begin{array}{l}
\mathrm{a}=\mathrm{D}_{1} \mathrm{a}_{1}+\mathrm{D}_{2} \mathrm{a}_{2} \\
\mathrm{~b}=\mathrm{D}_{1} \mathrm{~b}_{1}+\mathrm{D}_{2} \mathrm{~b}_{2} \\
\mathrm{c}=\mathrm{D}_{1} \mathrm{c}_{1}+\mathrm{D}_{2} \mathrm{c}_{2} \\
\mathrm{e}=\mathrm{D}_{1} \mathrm{e}_{1}+\mathrm{D}_{2} \mathrm{e}_{2}
\end{array}\right\}
$$

The steady state DC components of the system are:

$\mathrm{X}=$ steady state $\mathrm{DC}$ state vector.

$\mathrm{U}=$ steady state $\mathrm{DC}$ input vector.

$\mathrm{Y}=$ steady state DC output vector.

$\mathrm{D}_{1}=$ steady state $\mathrm{DC}$ duty cycle.

$\mathrm{D}_{2}=1-\mathrm{D}_{1}$

The averaging state space vector of the steady state and the output vector can be as the equations below by solving (10):

$$
\left.\begin{array}{l}
X=-\frac{b U}{a} \\
Y=\left(\frac{-c b}{a}+e\right) U
\end{array}\right\}
$$

The AC small signal model can be written as the following state equations:

$\mathrm{K} \nabla \hat{\mathrm{x}}(\mathrm{t})=\mathrm{a} \hat{\mathrm{x}}(\mathrm{t})+\mathrm{b} \hat{\mathrm{u}}(\mathrm{t})+\left[\left(\mathrm{a}_{1}-\mathrm{a}_{2}\right) \mathrm{X}+\left(\mathrm{b}_{1}-\mathrm{b}_{2}\right) \mathrm{U}\right] \hat{\mathrm{d}}(\mathrm{t})$

$\hat{y}(t)=c \hat{x}(t)+e \hat{u}(t)+\left[\left(c_{1}-c_{2}\right) X+\left(e_{1}-e_{2}\right) U\right] \hat{d}(t)$

Where: $\hat{x}(t), \hat{u}(t), \hat{y}(t)$ and $\hat{d}(t)$ in (13) are the quantities of the AC small variations in the steady state solution [1]. The equations (8) and (9) represent the state space equations of the converter and the equations from 
(10) to (13) are used to find averaged DC components and AC small signal models.

\section{AC SMALL SIGNAL MODEL OF THE ZSI}

The simplified equivalent circuit of ZSI is shown in Fig. 8(a). This circuit consists of two switching state depending on two switches S1 and S2 as depicted in Fig. 8(b) and Fig. 8(c). The first switching state that called active state occurred when S1 is "on" and S2 is "off". At this state, the energy transfer from DC voltage source passing through the inductances of ZSI to the load. The second switching state occurs when S1 is "off" and S2 is "on", in this state the energy doesn't transfer from DC voltage source to the load since the DC voltage source and the load are isolated and the capacitances of the ZSI charge the inductances of the ZSI. The shoot-through duty ratio D1 is depending on the interval of switching S2.

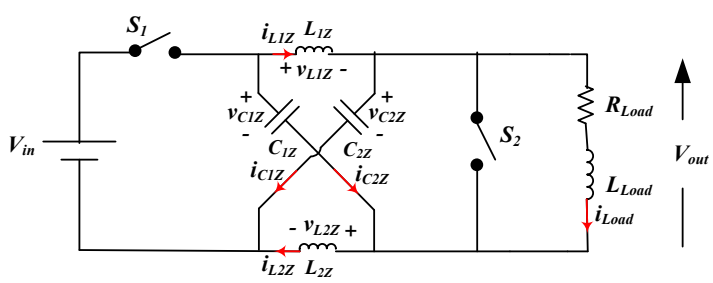

(a)

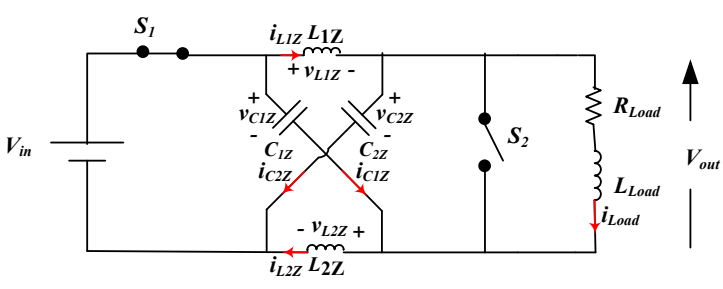

(b)

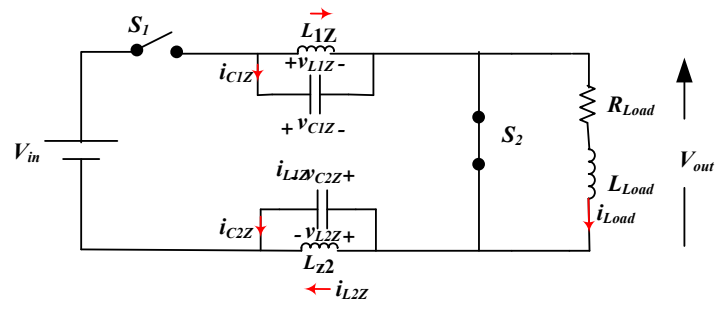

(c)

Fig. 8. (a) Simplified equivalent circuit of ZSI. (b) Active switching state. (c) Shoot-through switching state.

The AC side of the equivalent circuit can be represented as an equivalent DC load $\left(Z_{\text {Load }}\right)$ [11]. $Z_{\text {Load }}$ is equal to $R_{\text {Load }}+S L_{\text {Load }}$, where $R_{\text {Load }}$ is equal to $8\left|Z_{A C}\right| / 3 \cos \varphi$ that can be calculated by balance the power of the actual ZSI circuit that depicted in Fig. 2 and the equivalent circuit of ZSI that depicted in Fig. 8(a), where $\left|Z_{A C}\right|$ is the magnitude impedance/phase of the $\mathrm{AC}$ load and since the time constant of the DC load is equal to that in the AC load, so $L_{\text {Load }}$ can be determined as: $\frac{\left(L_{\text {Load }}\right)_{D C}}{\left(R_{\text {Load }}\right)_{D C}}=\frac{L_{A C}}{R_{A C}}$ where $R_{A C}$ is the resistance/phase of the AC load and $L_{A C}$ is the inductance/phase of the AC load. The ZSI is symmetrical because $L_{1 z}=L_{2 z}=L_{z}$ and $C_{1 z}=$
$C_{2 Z}=C_{Z}$, therefore $v_{C 1 Z}(t)=v_{C 2 Z}(t)=v_{C Z}(t)$ and $i_{L 1 Z}(t)$ $=i_{L 2 Z}(t)=i_{L Z}(t)[7]$.

There are three state variables in the ZSI, these state variables are the current that passing through the inductance, the voltage across the capacitance and the current of the inductive load. These variables can be represented as the vector:

$$
x(t)=\left[i_{L 1 Z}(t) i_{L 2 Z}(t) v_{C 1 Z}(t) v_{C 2 Z}(t) i_{\text {Load }}(t)\right]^{T}
$$

While at the shoot-through state that shown in Fig. 8(c), the equation of this state can be represented as the form $K \nabla x=a_{1} x+b_{1} u$ that given in (8) is written as the equation below:

$$
\begin{aligned}
& {\left[\begin{array}{ccccc}
L_{1 z} & 0 & 0 & 0 & 0 \\
0 & L_{2 z} & 0 & 0 & 0 \\
0 & 0 & C_{1 z} & 0 & 0 \\
0 & 0 & 0 & C_{2 z} & 0 \\
0 & 0 & 0 & 0 & L_{\text {Load }}
\end{array}\right] \nabla\left[\begin{array}{l}
i_{L 1 Z}(t) \\
i_{L 2 Z}(t) \\
v_{C 1 Z}(t) \\
v_{C 2 Z}(t) \\
i_{L o a d}(t)
\end{array}\right]=} \\
& {\left[\begin{array}{ccccc}
0 & 0 & 1 & 0 & 0 \\
0 & 0 & 0 & 1 & 0 \\
-1 & 0 & 0 & 0 & 0 \\
0 & -1 & 0 & 0 & 0 \\
0 & 0 & 0 & 0 & -R_{\text {Load }}
\end{array}\right]\left[\begin{array}{l}
i_{L 1 Z}(t) \\
i_{L 2 Z}(t) \\
v_{C 1 Z}(t) \\
v_{C 2 Z}(t) \\
i_{\text {Load }}(t)
\end{array}\right]}
\end{aligned}
$$

Where: $\nabla=d / d t$,

$$
\begin{gathered}
K=\left[\begin{array}{ccccc}
L_{1 z} & 0 & 0 & 0 & 0 \\
0 & L_{2 z} & 0 & 0 & 0 \\
0 & 0 & C_{1 z} & 0 & 0 \\
0 & 0 & 0 & C_{2 z} & 0 \\
0 & 0 & 0 & 0 & L_{\text {Load }}
\end{array}\right], a_{1}= \\
{\left[\begin{array}{cccccc}
0 & 0 & 1 & 0 & 0 \\
0 & 0 & 0 & 1 & 0 \\
-1 & 0 & 0 & 0 & 0 \\
0 & -1 & 0 & 0 & 0 \\
0 & 0 & 0 & 0 & -R_{\text {Load }}
\end{array}\right] \text { and } b_{1}=\left[\begin{array}{l}
0 \\
0 \\
0 \\
0 \\
0
\end{array}\right]}
\end{gathered}
$$

By the same way, the equation of state space at the active states that shown in Fig. 8(b) can also be represented as the form $K \nabla x_{(t)}=a_{2} x+b_{2} u$ that given in (9) is written as:

$$
\begin{aligned}
& {\left[\begin{array}{ccccc}
L_{1 z} & 0 & 0 & 0 & 0 \\
0 & L_{2 z} & 0 & 0 & 0 \\
0 & 0 & C_{1 z} & 0 & 0 \\
0 & 0 & 0 & C_{2 z} & 0 \\
0 & 0 & 0 & 0 & L_{\text {Load }}
\end{array}\right] \nabla\left[\begin{array}{c}
i_{L 1 Z}(t) \\
i_{L 2 Z}(t) \\
v_{C 1 Z}(t) \\
v_{C 2 Z}(t) \\
i_{\text {Load }}(t)
\end{array}\right]=} \\
& {\left[\begin{array}{ccccc}
0 & 0 & 0 & -1 & 0 \\
0 & 0 & -1 & 0 & 0 \\
0 & 1 & 0 & 0 & -1 \\
1 & 0 & 0 & 0 & -1 \\
0 & 0 & 1 & 1 & -R_{\text {Load }}
\end{array}\right]\left[\begin{array}{c}
i_{L 1 Z}(t) \\
i_{L 2 Z}(t) \\
v_{C 1 Z}(t) \\
v_{C 2 Z}(t) \\
i_{\text {Load }}(t)
\end{array}\right]+} \\
& {\left[\begin{array}{c}
1 \\
1 \\
0 \\
0 \\
-1
\end{array}\right] V_{\text {in }}(t)}
\end{aligned}
$$


Equations (14) and (15) show the relation between the three state variables $\left(i_{L Z}, v_{C Z}\right.$ and $\left.i_{\text {Load }}\right)$ [7] and the input such as $V_{i n}$ during the shoot-through state and the active states. These two equations diversify the state space model of ZSI. It's known from the previous section that this model of ZSI can be used for averaging state space and find the equation of it at the equilibrium (steady state) and the model of AC small signal [11].

Equation (16) represents the model of the averaging state space. This equation describes the state space equations at the steady state (equilibrium) that based on (10) and (11).

$\left[\begin{array}{l}0 \\ 0 \\ 0 \\ 0 \\ 0\end{array}\right]=\left[\begin{array}{ccccc}0 & 0 & D_{1} & -D_{2} & 0 \\ 0 & 0 & -D_{2} & D_{1} & 0 \\ -D_{1} & D_{2} & 0 & 0 & -D_{2} \\ D_{2} & -D_{1} & 0 & 0 & -D_{2} \\ 0 & 0 & D_{2} & D_{2} & -R_{\text {Load }}\end{array}\right]\left[\begin{array}{c}I_{L 1 z} \\ I_{L 2 z} \\ V_{C 1 z} \\ V_{C 2 z} \\ I_{\text {Load }}\end{array}\right]+\left[\begin{array}{c}D_{2} \\ D_{2} \\ 0 \\ 0 \\ -D_{2}\end{array}\right] V_{\text {in }}$

Where $D_{1}$ is the duty ratio when $\mathrm{S} 1$ is off and $\mathrm{S} 2$ is on, $D_{2}$ is the duty ratio when $\mathrm{S} 1$ is on and $\mathrm{S} 2$ is off, $I_{L 1 z}, I_{L 2 z}$, $V_{C 1 z}, V_{C 2 z}, I_{\text {Load }}$ and $V_{\text {in }}$ are the DC steady state values. The state vector of the equilibrium can be found by solving (16). Equation (10) that wrote in the previous section can be used to find the steady state values of the state variables that written as:

$$
\begin{aligned}
& V_{C Z}=\frac{D_{2}}{D_{2}-D_{1}} V_{\text {in }} \\
& I_{L Z}=\frac{D_{2}}{D_{2}-D_{1}} I_{\text {Load }} \\
& I_{\text {Load }}=\frac{V_{C Z}}{R_{\text {Load }}}
\end{aligned}
$$

For determining the dynamic behavior of the state variables, the input voltage $V_{\text {in }}$ and steady state DC duty cycle $D_{1}$ must be perturbed around their equilibrium values and these can be written as:

$$
\begin{aligned}
& v_{i n}(t)=V_{i n}+\hat{v}_{i n}(t) \\
& d_{1}(t)=D_{1}+\hat{d}_{1}(t)
\end{aligned}
$$

Where $\hat{v}_{\text {in }}$ and $\hat{d}_{1}$ are the perturbed values of the input voltage $V_{\text {in }}$ and the steady state DC duty cycle $D_{1}$.

Generally the state variables small signal perturbations are represented by the general formula:

$$
x(t)=X+\hat{x}(t)
$$

Where: $\mathrm{x}(t)$ is the state variables.

\section{$\hat{x}(t)$ is the small signal perturbations}

$X$ is the steady state values of the state

variables.

By linearizing the averaged model and subtracting the steady state values of such steady state variables that obtained from (11), the small signal AC model's state equations can be found. And hence the open form of the AC small signal model equations of the ZSI can be formulated as:

$$
\begin{gathered}
{\left[\begin{array}{ccccc}
L_{1 z} & 0 & 0 & 0 & 0 \\
0 & L_{2 z} & 0 & 0 & 0 \\
0 & 0 & C_{1 z} & 0 & 0 \\
0 & 0 & 0 & C_{2 z} & 0 \\
0 & 0 & 0 & 0 & L_{\text {Load }}
\end{array}\right] \nabla\left[\begin{array}{c}
\hat{\imath}_{L 1 Z}(t) \\
\hat{\imath}_{L 2 Z}(t) \\
\hat{v}_{C 1 Z}(t) \\
\hat{v}_{C 2 Z}(t) \\
\hat{\imath}_{\text {Load }}(t)
\end{array}\right]=} \\
{\left[\begin{array}{ccccc}
0 & 0 & D_{1} & -D_{2} & 0 \\
0 & 0 & -D_{2} & D_{1} & 0 \\
-D_{1} & D_{2} & 0 & 0 & -D_{2} \\
D_{2} & -D_{1} & 0 & 0 & -D_{2} \\
0 & 0 & D_{2} & D_{2} & -R_{L o a d}
\end{array}\right]\left[\begin{array}{c}
\hat{\imath}_{L 1 Z}(t) \\
\hat{\imath}_{L 2 Z}(t) \\
\hat{v}_{C 1 Z}(t) \\
\hat{v}_{C 2 Z}(t) \\
\hat{\imath}_{L o a d}(t)
\end{array}\right]+} \\
{\left[\begin{array}{c}
D_{2} \\
D_{2} \\
0 \\
0 \\
-D_{2}
\end{array}\right] \hat{v}_{\text {in }}(t)+\left[\begin{array}{c}
V_{C 1 Z}+V_{C 2 Z}-V_{\text {in }} \\
-I_{L 1 Z}-I_{C 2 Z}-V_{\text {in }} \\
-I_{L 1 Z}-I_{L 2 Z}+I_{L o a d} \\
-V_{C 1 Z}-V_{C 2 Z}+V_{\text {in }}
\end{array}\right] \hat{d}_{1}(t)}
\end{gathered}
$$

Equations from (24) to (28) are obtained by using the Laplace form of (23) which can be written as:

$$
\begin{aligned}
& S L_{1 z} \hat{\imath}_{L 1 z}(s)=D_{1} \hat{v}_{C 1 z}(s)-D_{2} \hat{v}_{C 2 z}(s)+D_{2} \hat{v}_{i n}(s)+ \\
& \left(V_{C 1 z}+V_{C 2 z}-V_{\text {in }}\right) \hat{d}_{1}(s) \\
& S L_{2 z} \hat{\imath}_{L 2 z}(s)=-D_{2} \hat{v}_{C 1 z}(s)+D_{1} \hat{v}_{C 2 z}(s)+D_{2} \hat{v}_{i n}(s)+ \\
& \left(V_{C 1 z}+V_{C 2 z}-V_{\text {in }}\right) \hat{d}_{1}(s) \\
& S C_{1 z} \hat{v}_{C 1 z}(s)=-D_{1} \hat{\imath}_{L 1 z}(s)+D_{2} \hat{\imath}_{L 2 z}(s)-D_{2} \hat{\imath}_{L o a d}(s)+ \\
& \left(-I_{L 1 z}-I_{L 2 z}+I_{L o a d}\right) \hat{d}_{1}(s) \\
& S C_{2 z} \hat{v}_{C 2 z}(s)=D_{2} \hat{l}_{L 1 z}(s)-D_{1} \hat{\imath}_{L 2 z}(s)-D_{2} \hat{\imath}_{L o a d}(s)+ \\
& \left(-I_{L 1 z}-I_{L 2 z}+I_{L o a d}\right) \hat{d}_{1}(s) \\
& S L_{\text {Load }} \hat{\imath}_{L o a d}(s)=D_{2} \hat{v}_{C 1 z}(s)+D_{2} \hat{v}_{C 2 z}(s)- \\
& R_{\text {Load }} \hat{\imath}_{\text {Load }}(s)-D_{2} \hat{v}_{i n}(s)+\left(-V_{C 1 z}-V_{C 2 z}+V_{\text {in }}\right) \hat{d}_{1}(s)
\end{aligned}
$$

Since $L_{1 z}=L_{2 z}=L_{z}$ and $C_{1 z}=C_{2 z}=C_{z}$ and $D_{2}=1-D_{1}$

By subtracting (25) from (24), we get:

$$
\hat{\imath}_{L 1 Z}(s)-\hat{\imath}_{L 2 Z}(s)=\frac{1}{S L_{Z}}\left[\hat{v}_{C 1 Z}(s)-\hat{v}_{C 2 Z}(s)\right]
$$

And also by subtracting (27) and (26), we get:

$$
\left[\hat{v}_{C 1 Z}(s)-\hat{v}_{C 2 Z}(s)\right]=\frac{1}{S C_{Z}}\left[\hat{l}_{L 1 Z}(s)-\hat{\imath}_{L 2 Z}(s)\right]
$$

Substituting (29) in (30) and using Laplace transformation, we get:

$$
\left(1+S^{2} L_{z} C_{z}\right) \cdot\left[\hat{v}_{C 1 Z}(t)-\hat{v}_{C 2 Z}(t)\right]=0
$$

Equation (3.25) is pointed to that for all non-resonance frequencies $\left(1+S^{2} L_{z} C_{z}\right) \neq 0, \quad \hat{v}_{C 1 Z}(t)=\hat{v}_{C 2 z}(t)=$ $\hat{v}_{C Z}(t)$ and $\hat{\imath}_{L 1 Z}(t)=\hat{\imath}_{L 2 Z}(t)=\hat{\imath}_{L Z}(t)$.

And since ZSI is symmetrical so $I_{L 1 Z}=I_{L 2 Z}=I_{L Z}$ and $V_{C 1 Z}=V_{C 2 Z}=V_{C Z}$.

Equations from (24) to (29) can be simplified to;

$$
\begin{gathered}
S L_{z} \hat{\imath}_{L z}(s)=\left(D_{1}-D_{2}\right) \hat{v}_{C z}(s)+D_{2} \hat{v}_{\text {in }}(s)+V_{\text {out }} \hat{d}_{1}(s) \\
S C_{z} \hat{v}_{C Z}(s)=\left(D_{2}-D_{1}\right) \hat{\imath}_{L z}(s)-D_{2} \hat{l}_{\text {Load }}(s)+ \\
\left(-2 I_{L z}+I_{\text {Load }}\right) \hat{d}_{1}(s) \\
S L_{\text {Load }} \hat{\imath}_{\text {Load }}(s)=2 D_{2} \hat{v}_{C z}(s)-R_{\text {Load }} \hat{\imath}_{\text {Load }}(s)- \\
D_{2} \hat{v}_{\text {in }}(s)+V_{\text {out }} \hat{d}_{1}(s)
\end{gathered}
$$



$V_{\text {in }}$.

Where: $V_{\text {out }}$ is the steady state output voltage $=2 V_{C Z}-$

The AC small signal circuit can be constructed by using the equation of the steady state and AC small signal. There are three equivalent circuits as depicted in Fig. 7 [12]. Each one of these three circuits is based on one of the (32), (33), and (34) and has two sources, the independent sources such as $\hat{d}_{1}(t)$ and $\hat{v}_{i n}(t)$, and dependent sources that depending on the currents and voltages in the Zsource inverter such as $\hat{v}_{C Z}(t), \hat{\imath}_{L Z}(t)$.
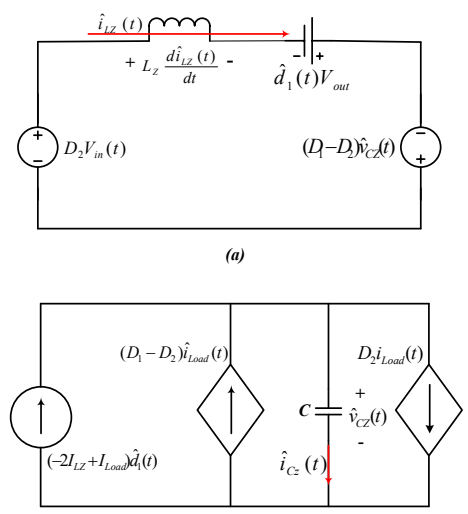

(b)

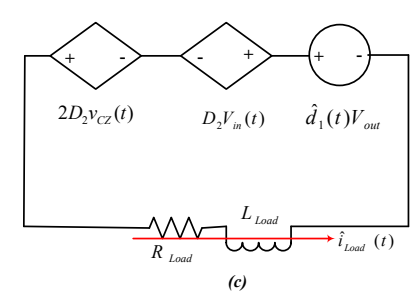

Fig. 9. Equivalent circuit of AC small signal

The equations of $\mathrm{AC}$ small signal for the three state variables in (32), (33), and (34) are represented as a subcircuit that depicted in Fig. 9. (a), (b) and (c). The three state variables in the ZSI are the inductance current, the capacitance voltage, and the load current.

There are two sources perturbations to analyze the AC small signal; these sources are the shoot-through duty cycle perturbation $\hat{d}_{1}(t)$ and the input voltage perturbation $\hat{v}_{i n}$. When a state variable perturbs, it can be represented as a linear combination of AC small signal perturbations for all sources. The expressions of the AC small signal for the capacitance voltage and the inductance current respectively are written in (35) and (36).

$$
\begin{aligned}
& \tilde{v}_{C Z}(s)=G_{v_{C Z / i n}}(s) \cdot \hat{v}_{i n}(s)+G_{v_{C Z / d_{1}}}(s) \cdot \hat{d}_{1}(s) \\
& \tilde{i}_{L Z}(s)=G_{i_{L Z / i n}}(s) \cdot \hat{v}_{i n}(s)+G_{i_{L Z / d_{1}}}(s) \cdot \hat{d}_{1}(s)
\end{aligned}
$$

Where: $G_{v_{c z / i n}}(s)$ is the disturbance-to-capacitance voltage transfer function, $G_{v_{C Z / d_{1}}}(s)$ is the control-tocapacitance voltage transfer function, $G_{i_{L z / i n}}(s)$ is the disturbance-to-inductance current transfer function, $G_{i_{L z / d_{1}}}(s)$ is the control-to-inductance current transfer function.

The transfer function of the disturbance-to-capacitance voltage $\left\{G_{v_{C z / i n}}(s)\right\}$ can be obtained as the following procedures:

Substituting $\hat{d}_{1}(s)=0$ in (33):

$S C_{z} \hat{v}_{C Z}(s)=\left(D_{2}-D_{1}\right) \hat{\imath}_{L Z}(s)-D_{2} \hat{\imath}_{\text {Load }}(s)$

Substituting $\hat{d}_{1}(s)=0$ in (32):

$\hat{\imath}_{L Z}(s)=\frac{\left(D_{1}-D_{2}\right) \hat{v}_{C Z}(s)+D_{2} \hat{v}_{i n}(s)}{S L_{Z}}$

Substituting (38) in (37):

$S C_{z} \hat{v}_{C Z}(s)=\left(D_{2}-D_{1}\right) \frac{\left(D_{1}-D_{2}\right) \hat{v}_{C Z}(s)+D_{2} \hat{v}_{\text {in }}(s)}{S L_{z}}-D_{2} \hat{l}_{\text {Load }}(s)$

Substituting $\hat{d}_{1}(s)=0$ in (34):

$$
\begin{aligned}
& S L_{z} \hat{\imath}_{\text {Load }}(s)=2 D_{2} \hat{v}_{C Z}(s)-R_{\text {Load }} \hat{l}_{\text {Load }}(s)-D_{2} \hat{v}_{\text {in }}(s) \\
& \left(S L_{z}+R_{\text {Load }}\right) \hat{\imath}_{\text {Load }}(s)=2 D_{2} \hat{v}_{C Z}(s)-D_{2} \hat{v}_{\text {in }}(s) \\
& \hat{\imath}_{\text {Load }}(s)=\frac{\left(2 D_{2} \hat{v}_{C Z}(s)-D_{2} \hat{v}_{\text {in }}(s)\right)}{\left(R_{\text {Load }}+S L_{\text {Load }}\right)}
\end{aligned}
$$


Substituting (40) in (39):

$S C_{z} \hat{v}_{C Z}(s)=\left(D_{2}-D_{1}\right)\left(\frac{\left(D_{1}-D_{2}\right) \hat{v}_{C Z}(s)}{S L_{z}}+\frac{D_{2} \hat{v}_{\text {in }}(s)}{S L_{z}}\right)-D_{2}\left(\frac{2 D_{2} \hat{v}_{C Z}(s)}{\left(R_{\text {Load }}+S L_{\text {Load }}\right)}-\frac{D_{2} \hat{v}_{\text {in }}(s)}{\left(R_{\text {Load }}+S L_{\text {Load }}\right)}\right)$
$S C_{z} \hat{v}_{C Z}(s)=\frac{\left(D_{1}-D_{2}\right)^{2}}{S L_{z}} \hat{v}_{C Z}(s)+\frac{D_{2}\left(D_{2}-D_{1}\right)}{S L_{z}} \hat{v}_{\text {in }}(s)-\frac{2 D_{2}{ }^{2}}{\left(R_{\text {Load }}+S L_{\text {Load }}\right)} \hat{v}_{C Z}(s)+\frac{D_{2}{ }^{2}}{\left(R_{\text {Load }}+S L_{\text {Load }}\right)} \hat{v}_{\text {in }}(s)$
$\left(S C_{z}+\frac{\left(D_{1}-D_{2}\right)^{2}}{S L_{z}}+\frac{2 D_{2}{ }^{2}}{\left(R_{\text {Load }}+S L_{\text {Load }}\right)}\right) \hat{v}_{C Z}(s)=\frac{D_{2}\left(D_{2}-D_{1}\right)}{S L_{z}} \hat{v}_{\text {in }}(s)+\frac{D_{2}{ }^{2}}{\left(R_{\text {Load }}+S L_{\text {Load }}\right)} \hat{v}_{\text {in }}(s)$
$\left(\frac{S^{2} L_{z} C_{Z}+\left(D_{1}-D_{2}\right)^{2}+\frac{2 D_{2}{ }^{2}}{Z_{\text {Load }}} L_{z} S}{S L_{z}}\right) \hat{v}_{C Z}(s)=\left(\frac{D_{2}\left(D_{2}-D_{1}\right)+\frac{D_{2}{ }^{2}}{Z_{\text {Load }}} L_{Z} S}{S L_{Z}}\right) \hat{v}_{\text {in }}(s)$

Where: $Z_{\text {Load }}=R_{\text {Load }}+S L_{\text {Load }}$

$\left(S^{2} L_{z} C_{z}+\left(D_{1}-D_{2}\right)^{2}+\frac{2 D_{2}{ }^{2}}{Z_{\text {Load }}} L_{z} S\right) \hat{v}_{C z}(s)=\left(D_{2}\left(D_{2}-D_{1}\right)+\frac{D_{2}{ }^{2}}{Z_{\text {Load }}} L_{z} S\right) \hat{v}_{\text {in }}(s)$

$G_{v_{C Z / i n}}(s)=\left.\frac{\hat{v}_{C Z}(s)}{\hat{v}_{\text {in }}(s)}\right|_{\hat{d}_{1}(s)=0}=\frac{\frac{D_{2}^{2}}{Z_{\text {Load }}} L_{Z} S+D_{2}\left(D_{2}-D_{1}\right)}{S^{2} L_{Z} C_{Z}+\frac{2 D_{2}^{2}}{Z_{\text {Load }}} L_{Z} S+\left(D_{1}-D_{2}\right)^{2}}$

Dividing (42) by $Z_{\text {Load }}$ :

$G_{v_{C Z / i n}}(s)=\left.\frac{\hat{v}_{C Z}(s)}{\hat{v}_{\text {in }}(s)}\right|_{\hat{d}_{1}(s)=0}=\frac{D_{2}{ }^{2} L_{Z} S+D_{2}\left(D_{2}-D_{1}\right) R_{\text {Load }} S+D_{2}\left(D_{2}-D_{1}\right) S L_{\text {Load }}}{L_{\text {Load }} L_{Z} C_{Z} S^{3}+R_{\text {Load }} L_{Z} C_{Z} S^{2}+\left(D_{1}-D_{2}\right)^{2} L_{\text {Load }} S+2 D_{2}{ }^{2} L_{Z} S+\left(D_{1}-D_{2}\right)^{2} R_{\text {Load }}}$

The transfer function of the control-to-capacitance voltage $\left\{G_{v_{C z / d_{1}}}(s)\right\}$ can be obtained as the following procedure:

Substituting $\hat{v}_{\text {in }}(s)=0$ in $(32)$ :

$\hat{\imath}_{L Z}(s)=\frac{\left(D_{1}-D_{2}\right) \hat{v}_{C Z}(s)+V_{o u t} \hat{d}_{1}(s)}{S L_{Z}}$

Substituting $\hat{v}_{\text {in }}(s)=0$ and (43) in (33):

$$
\begin{aligned}
& S C_{z} \hat{v}_{C Z}(s)=\left(D_{2}-D_{1}\right)\left(\frac{\left(D_{1}-D_{2}\right) \hat{v}_{C Z}(s)+V_{o u t} \hat{d}_{1}(s)}{S L_{Z}}\right)-D_{2} \hat{\imath}_{\text {Load }}(s)+\left(-2 I_{L Z}+I_{\text {Load }}\right) \hat{d}_{1}(s) \\
& \left(\frac{L_{Z} C_{Z} S^{2}+\left(D_{1}-D_{2}\right)^{2}}{S L_{z}}\right) \hat{v}_{C Z}(s)=\left(\frac{\left(D_{2}-D_{1}\right) V_{o u t}+\left(-2 I_{L z}+I_{L o a d}\right) L_{Z} S}{S L_{Z}}\right) \hat{d}_{1}(s)-D_{2} \hat{\imath}_{\text {Load }}(s)
\end{aligned}
$$

Substituting $\hat{v}_{\text {in }}(s)=0$ in (34):

$S L_{\text {Load }} \hat{\imath}_{\text {Load }}(s)=2 D_{2} \hat{v}_{C z}(s)-R_{\text {Load }} \hat{\imath}_{\text {Load }}(s)+V_{\text {out }} \hat{d}_{1}(s)$

$\left(S L_{\text {Load }}+R_{\text {Load }}\right) \hat{\imath}_{\text {Load }}(s)=2 D_{2} \hat{v}_{C z}(s)+V_{\text {out }} \hat{d}_{1}(s)$

$\hat{\imath}_{\text {Load }}(s)=\frac{2 D_{2} \hat{v}_{C Z}(s)}{\left(S L_{\text {Load }}+R_{\text {Load }}\right)}+\frac{V_{\text {out }} \hat{d}_{1}(s)}{\left(S L_{\text {Load }}+R_{\text {Load }}\right)}$

Substituting (45) in (44)

$$
\begin{aligned}
& \left(\frac{L_{Z} C_{Z} S^{2}+\left(D_{1}-D_{2}\right)^{2}+\frac{2 D_{2}{ }^{2} L_{Z} S}{Z_{\text {Load }}}}{S L_{Z}}\right) \hat{v}_{C Z}(S)=\left(\frac{\left(D_{2}-D_{1}\right) V_{\text {out }}+\left(-2 I_{L Z}+I_{\text {Load }}\right) L_{Z} S+\frac{D_{2} V_{\text {out }} L_{Z} S}{Z_{\text {Load }}}}{S L_{Z}}\right) \hat{d}_{1}(s) \\
& \left(L_{Z} C_{Z} S^{2}+\left(D_{1}-D_{2}\right)^{2}+\frac{2 D_{2}{ }^{2} L_{Z} S}{Z_{\text {Load }}}\right) \hat{v}_{C Z}(S)=\left(\left(D_{2}-D_{1}\right) V_{\text {out }}+\left(-2 I_{\text {LZ }}+I_{\text {Load }}\right) L_{Z} S+\frac{D_{2} V_{\text {out }} L_{Z} S}{Z_{\text {Load }}}\right) \hat{d}_{1}(s) \\
& G_{v_{C Z} / d_{1}}(s)=\left.\frac{\hat{v}_{C Z}(s)}{\hat{d}_{1}(s)}\right|_{\hat{v}_{\text {in }}(s)=0}=\frac{\left(\left(-2 I_{L Z}+I_{\text {Load }}\right) L_{Z}+\frac{D_{2} V_{\text {out }} L_{Z}}{Z_{\text {Load }}}\right) S+\left(D_{2}-D_{1}\right) V_{\text {out }}}{L_{Z} C_{Z} S^{2}+\frac{2 D_{2}{ }^{2} L_{Z} S}{Z_{\text {Load }}}+\left(D_{1}-D_{2}\right)^{2}}
\end{aligned}
$$

Dividing (46) by $Z_{\text {Load }}$ :

$$
\begin{aligned}
& G_{v_{C Z} / d_{1}}(S)=\left.\frac{\hat{v}_{C Z}(s)}{\widehat{d}_{1}(s)}\right|_{\hat{v}_{\text {in }}(s)=0}=\frac{\left(\left(-2 I_{L Z}+I_{L o a d}\right)\left(S L_{\text {Load }}+R_{\text {Load }}\right) L_{Z}+D_{2} V_{\text {out }} L_{Z}\right) S+\left(D_{2}-D_{1}\right) V_{\text {out }}\left(S L_{\text {Load }}+R_{\text {Load }}\right)}{L_{z} C_{Z}\left(S L_{\text {Load }}+R_{\text {Load }}\right) S^{2}+2 D_{2}{ }^{2} L_{Z} S+\left(D_{1}-D_{2}\right)^{2}\left(S L_{L o a d}{ }^{+}\right.} \\
& G_{v_{C Z} / d_{1}}(s)=\left.\frac{\hat{v}_{C Z}(s)}{\hat{d}_{1}(s)}\right|_{\hat{v}_{\text {in }}(s)=0}=\frac{\left(-2 I_{L Z}+I_{\text {Load }}\right) L_{Z} L_{L o a d} S^{2}+\left(\left(-2 I_{L Z}+I_{L o a d}\right) R_{L o a d} L_{Z}+D_{2} V_{o u t} L_{Z}+\left(D_{2}-D_{1}\right) V_{\text {out }} L_{L o a d}\right) S+\left(D_{2}-D_{1}\right) V_{\text {out }} R_{\text {Load }}}{L_{Z} C_{Z} L_{L o a d} S^{3}+L_{Z} C_{Z} R_{L o a d} S^{2}+\left(2 D_{2}^{2} L_{Z}+\left(D_{1}-D_{2}\right)^{2} L_{L o a d}\right) S+}
\end{aligned}
$$


The transfer function of the disturbance-to- inductance current $\left(G_{i_{L Z} / i n}(s)\right)$ can be formed as the following procedure:

Substituting $\hat{d}_{1}(s)=0$ in (32):

$S L_{z} \hat{l}_{L Z}(s)=\left(D_{1}-D_{2}\right) \hat{v}_{C Z}(s)+D_{2} \hat{v}_{i n}(s)$

From (41):

$\hat{v}_{C Z}(s)=\frac{\frac{D_{2}^{2}}{Z_{\text {Load }}} L_{Z} S+D_{2}\left(D_{2}-D_{1}\right)}{S^{2} L_{Z} C_{Z}+\frac{2 D_{2}{ }^{2}}{Z_{\text {Load }}} L_{Z} S+\left(D_{1}-D_{2}\right)^{2}} \hat{v}_{\text {in }}(s)$

Substituting (49) in (48)

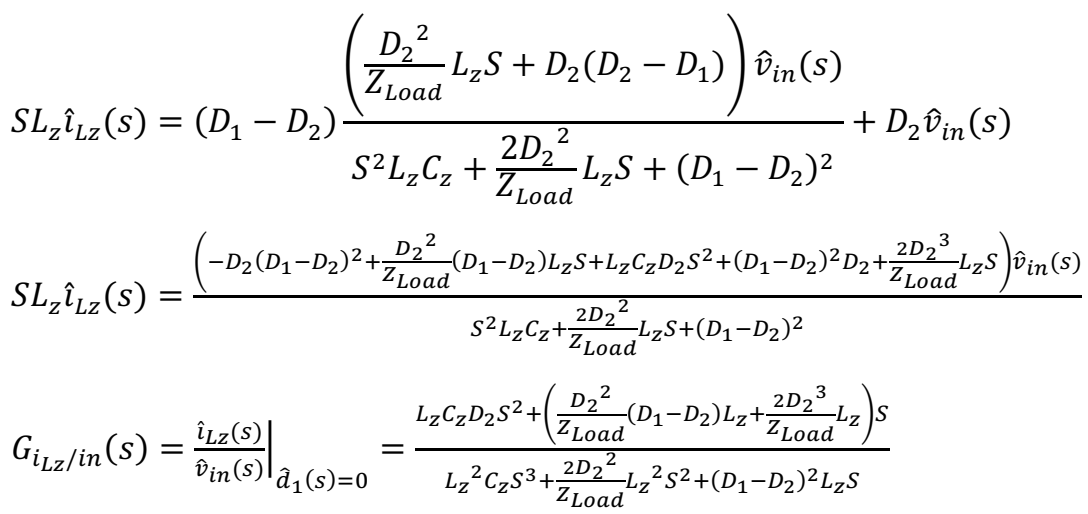

Dividing (50) by $Z_{\text {Load }}$ :

$G_{i_{L Z} / \text { in }}(s)=\left.\frac{\hat{\imath}_{L Z}(s)}{\hat{v}_{\text {in }}(s)}\right|_{\hat{d}_{1}(s)=0}=\frac{L_{Z} C_{Z} D_{2}\left(S L_{\text {Load }}+R_{\text {Load }}\right) S^{2}+\left(D_{2}{ }^{2}\left(D_{1}-D_{2}\right) L_{Z}+2 D_{2}{ }^{3} L_{Z}\right) S}{L_{z}{ }^{2} C_{Z}\left(S L_{\text {Load }}+R_{\text {Load }}\right) S^{3}+2 D_{2}{ }^{2} L_{z}{ }^{2} S^{2}+\left(D_{1}-D_{2}\right)^{2} L_{Z}\left(S L_{L o a d}+R_{\text {Load }}\right) S}$

$G_{i_{L Z} / \text { in }}(s)=\left.\frac{\hat{\imath}_{L Z}(s)}{\hat{v}_{\text {in }}(s)}\right|_{\hat{d}_{1}(s)=0}=\frac{L_{Z} C_{Z} D_{2} L_{L o a d} S^{3}+L_{z} C_{Z} D_{2} R_{\text {Load }} S^{2}+\left(\left(D_{1}-D_{2}\right)+2 D_{2}\right) D_{2}{ }^{2} L_{Z} S}{L_{Z}{ }^{2} C_{Z} R_{\text {Load }} S^{3}+L_{Z}{ }^{2} C_{Z} L_{L o a d} S^{4}+2 D_{2}{ }^{2} L_{Z}{ }^{2} S^{2}+\left(D_{1}-D_{2}\right)^{2} L_{Z} R_{\text {Load }} S+\left(D_{1}-D_{2}\right)^{2} L_{Z} L_{\text {Load }} S^{2}}$

$G_{i_{L Z} / \text { in }}(s)=\left.\frac{\hat{\imath}_{L Z}(s)}{\hat{v}_{\text {in }}(s)}\right|_{\hat{d}_{1}(s)=0}=\frac{C_{Z} D_{2} L_{L o a d} S^{2}+D_{2} C_{Z} R_{L o a d} S+D_{2}{ }^{2}}{C_{Z} L_{Z} L_{L o a d} S^{3}+L_{Z} C_{Z} R_{L o a d} S^{2}+\left(\left(D_{1}-D_{2}\right)^{2} L_{L o a d}+2 D_{2}{ }^{2} L_{Z}\right) S+\left(D_{1}-D_{2}\right)^{2} R_{L o a d}}$

The transfer function of the control-to- inductance current $\left\{G_{i_{L z} / \widehat{d}_{1}}(s)\right\}$ can be obtained by the following procedure:

Substituting $\hat{v}_{\text {in }}(s)=0$ in (32):

$\hat{\imath}_{L Z}(s)=\frac{\left(D_{1}-D_{2}\right) \hat{v}_{C Z}(s)+V_{o u t} \hat{d}_{1}(s)}{S L_{Z}}$

Substituting (46) in (52):

$S L_{z} \hat{\imath}_{L z}(s)=\left(D_{1}-D_{2}\right)\left(\frac{\left(\left(-2 I_{L z}+I_{\text {Load }}\right)+\frac{D_{2} V_{\text {out }}}{\left(S L_{\text {Load }}+R_{\text {Load }}\right)}\right) L_{z} S+\left(D_{2}-D_{1}\right) V_{\text {out }}}{L_{z} C_{z} S^{2}+\left(D_{1}-D_{2}\right)^{2}+\frac{2 D_{2}{ }^{2} L_{z} S}{Z_{\text {Load }}}}\right) \hat{d}_{1}(s)+V_{\text {out }} \hat{d}_{1}(s)$

$S L_{z} \hat{l}_{L Z}(s)=\left(\frac{\left(\left(-2 I_{\text {LZ }}+I_{\text {Load }}\right)+\frac{D_{2} V_{\text {out }}}{\left(S L_{\text {Load }}+R_{\text {Load }}\right)}\right)\left(D_{1}-D_{2}\right) L_{Z} S-\left(D_{1}-D_{2}\right)^{2} V_{\text {out }}+L_{Z} C_{Z} V_{\text {out }} S^{2}+\left(D_{1}-D_{2}\right)^{2} V_{\text {out }}+\frac{2 D_{2}{ }^{2} L_{Z}}{Z_{\text {Load }}} V_{\text {out }} S}{L_{Z} C_{Z} S^{2}+\left(D_{1}-D_{2}\right)^{2}+\frac{2 D_{2}{ }^{2} L_{Z} S}{Z_{\text {Load }}}}\right) \hat{d}_{1}(S)$

$G_{i_{L Z} / d_{1}}(s)=\left.\frac{\hat{\imath}_{L Z}(s)}{\hat{d}_{1}(s)}\right|_{\hat{v}_{\text {in }}(s)=0}=\frac{L_{Z} C_{Z} V_{\text {out }} S^{2}+\left(\left(-2 I_{L Z}+I_{\text {Load }}\right)\left(D_{1}-D_{2}\right) L_{Z}+\frac{D_{2} V_{\text {out }}}{\left(S L_{\text {Load }}+R_{\text {Load }}\right)}\left(D_{1}-D_{2}\right) L_{Z}+\frac{2 D_{2}{ }^{2} L_{Z}}{Z_{\text {Load }}} V_{\text {out }}\right) S}{L_{Z}{ }^{2} C_{Z} S^{3}+\frac{2 D_{2}^{2} L_{Z}{ }^{2}}{Z_{L o a d}} S^{2}+\left(D_{1}-D_{2}\right)^{2} L_{Z} S}$

Dividing (53) by $Z_{\text {Load }}$ :

$G_{i_{L Z} / d_{1}}(s)=\left.\frac{\hat{\imath}_{L Z}(s)}{\hat{d}_{1}(s)}\right|_{\hat{v}_{i n}(s)=0}=$

$L_{Z} C_{Z} V_{\text {out }} L_{\text {Load }} S^{3}+\left(L_{Z} C_{Z} V_{\text {out }} R_{\text {Load }}+\left(-2 I_{L z}+I_{\text {Load }}\right)\left(D_{1}-D_{2}\right) L_{\text {Load }} L_{Z}\right) S^{2}+\left(\left(-2 I_{L z}+I_{\text {Load }}\right)\left(D_{1}-D_{2}\right) R_{\text {Load }} L_{Z}+D_{2} V_{\text {out }}\left(D_{1}-D_{2}\right) L_{Z}+2 D_{2}{ }^{2} L_{Z} V_{\text {out }}\right) S$ $L_{z}{ }^{2} C_{Z} L_{\text {Load }} S^{4}+L_{z}{ }^{2} C_{Z} R_{\text {Load }} S^{3}+\left(2 D_{2}{ }^{2} L_{Z}{ }^{2}+\left(D_{1}-D_{2}\right)^{2} L_{Z} L_{\text {Load }}\right) S^{2}+\left(D_{1}-D_{2}\right)^{2} L_{Z} R_{\text {Load }} S$ 


\section{VERIFICATION OF ZSI MODEL}

The verification of AC small signal model that derived before can be made by simulating and comparing the dynamic behavior of actual ZSI switching circuit and the AC small signal circuit that depicted in Fig. 8 (a) and Fig. 9 respectively. Table (I) shows the used parameters of the ZSI. The state variables (inductance current $i_{L Z}$ and capacitance voltage $v_{C Z}$ ) in the ZSI are compared in two simulation cases. The first case shows the dynamic behavior of the voltage across the capacitance and the inductance current waveforms that gotten from the averaged model and the actual circuit at $10 \%$ increasing in duty ratio as depicted in Fig. 10 and Fig. 11. The second case shows the dynamic behavior of the same two state variables waveforms that also obtained from the averaged model and the actual circuit of ZSI at $10 \%$ sag in the input AC voltage $v_{s}$. Models simulations are implemented by using MATLABSIMULINK.

TABLE I: THE USED PARAMETERS OF THE ZSI

$\begin{array}{cc}\text { Input AC voltage }\left(\mathrm{v}_{\mathrm{s}}\right) & 200 \mathrm{~V} \\ \text { Inductance of ZSI }\left(\mathrm{L}_{\mathrm{z}}\right) & 250 \mu \mathrm{H} \\ \text { Capacitance of ZSI }\left(\mathrm{C}_{\mathrm{z}}\right) & 470 \mu \mathrm{F} \\ \text { Resistance of the load } & 17.8 \Omega \\ \left(\mathrm{R}_{\mathrm{Load}}\right) & \\ \text { Inductance of the load } & 11.9 \mathrm{mH} \\ \left(\mathrm{L}_{\mathrm{Load}}\right) & 10 \mathrm{KHz} \\ \text { Switching frequency }\left(\mathrm{f}_{\mathrm{sz}}\right) & 0.3 \\ \text { Initial duty ratio }\left(\mathrm{D}_{\mathrm{sh}}\right) & \end{array}$

The dynamic behavior of the capacitance voltage and the inductance current for the two cases (the changing in input voltage and duty ratio) that seen in Fig. 10 to Fig. 13 show that the mathematical model of $G_{v_{C Z} / \text { in }}$, $G_{v_{C Z} / d_{1}}, G_{i_{L Z} / d_{1}}, G_{i_{L Z} / \text { in }}$ and that derived from the AC small signal circuit in Fig. (3.2) is valid and can be used as the actual circuit of ZSI in Fig. 8 (a).

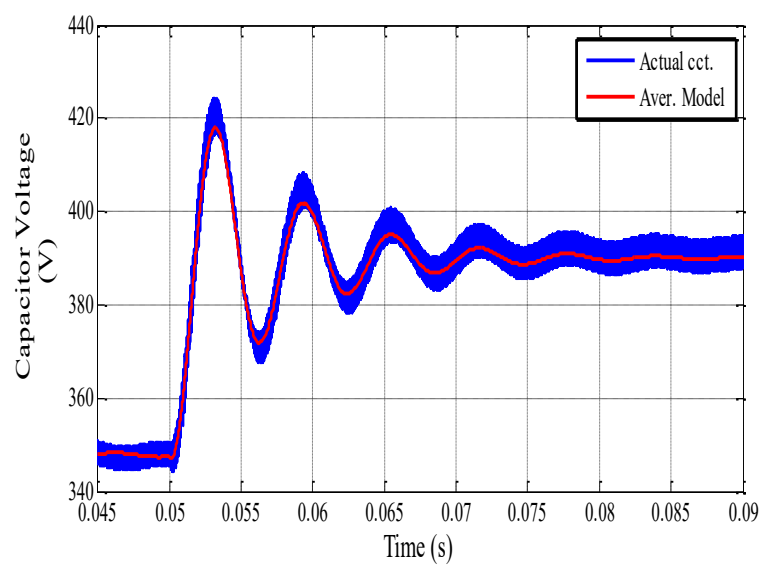

Fig. 10. The dynamic behaviors of the capacitance voltage $v_{C Z}$ at $10 \%$ changing in Dsh by using the actual circuit and the averaging model

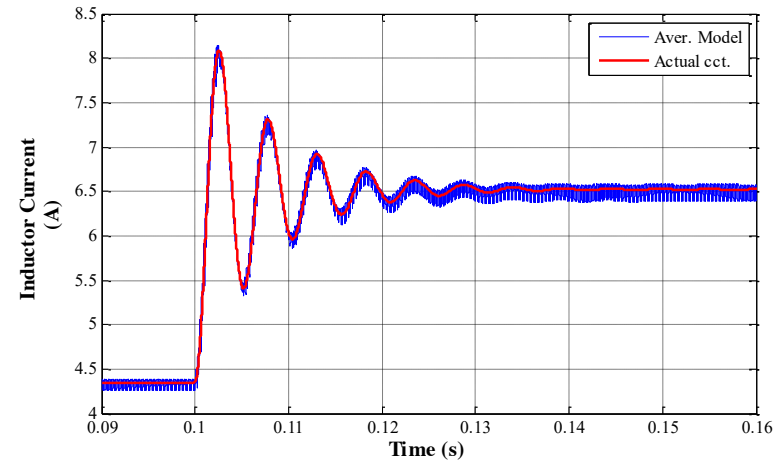

Fig. 11. The dynamic behaviors of the inductance current at $10 \%$ changing in $\mathrm{D}_{\mathrm{sh}}$ by using the actual circuit and the averaging model

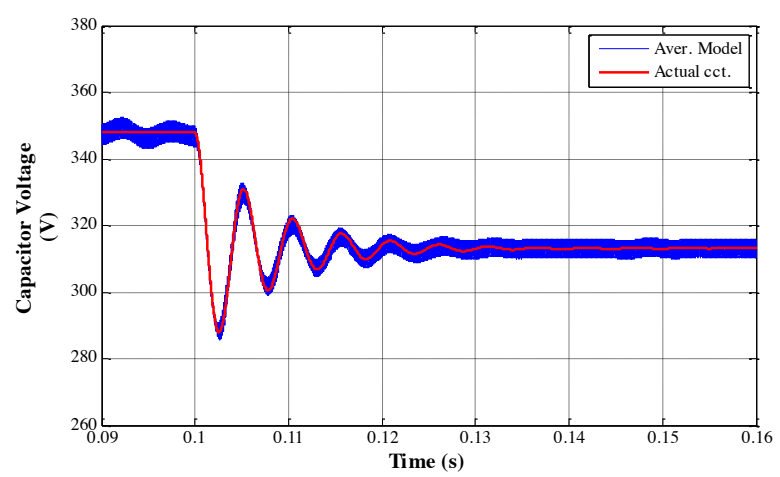

Fig. 12. The dynamic behaviors of the capacitance voltage $v_{C Z}$ at $10 \%$ voltage sag in $v_{S}$ by using the actual circuit and the averaging model

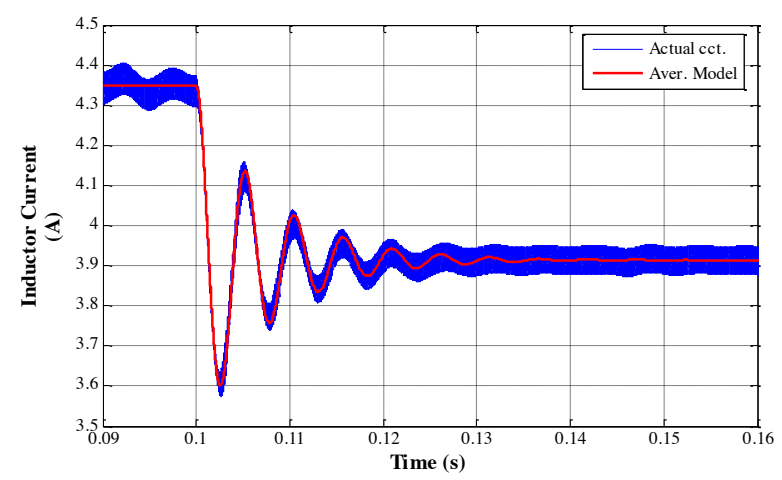

Fig. 13. The dynamic behaviors of the inductance current at $10 \%$ voltage sag in $v_{s}$ by using the actual circuit and the averaging model

\section{CONCLUSION}

This paper presents the analysis and the mathematical model of the Z-source inverter by circuit average model technique and state space averaging model technique to investigate the performance of the Z-Source Inverter. AC small signal perturbations are derived based on state space averaging model and state variables are linearization at equilibrium (steady state values) and analyzed to study the changes that occur in the behavior of ZSI such as change the input voltage, the current that pass through the load, or the shoot-through duty cycle. Moreover, the mathematical model gives the ability of choosing the optimal values of the capacitance and inductance of the Z-source network. The analytical results are verified by comparing them with that of the actual ZSI switching circuit analysis method. The 
comparison shows significant convergence between the presented analytical method and the actual ZSI analysis method. The percentage errors between the two methods, for both of the state variables (inductance current and capacitance voltage) in the ZSI, are very acceptable for major analysis requirements. The proposed model can replace the actual ZSI switching circuit model in an efficient manner in terms of the accuracy of the results.

\section{REFERENCES}

[1] R. W. Erickson and D. Maksimovic, "Fundamentals of Power Electronics", Kluwer Academic Publishers, Norwell MA, 2001.

[2] A. Das, D. Lahiri and B. Kar, "Space Vector PWM Based AC Outpu Voltage Control of Z - Source Inverter ", International Conference on Control, Automation, Communication and Energy Conservation, 4th6th June 2009

[3] J. G. Kassakian, M. F. Schlecht and G. C. Verghese, "Principles of Power Electronics", Addison-Wesley, Cambridge MA, 1991.

[4] V. Vorperian, "Simplified Analysis of PWM Converters Using the Model of the PWM Switch: Parts I and II", IEEE Transactions on Aerospace and Electronic Systems, vol. 26, May 1990, pp. 490-505.

[5] R. D. Middlebrook and S. Cuk, "A General Unified Approach to Modeling Switching-Converter Power Stages", International Journal of Electronics, Vol. 42, No. 6, June 1977, pp. 521-550.

[6] R. D. Middlebrook and S. Cuk, "Modeling and Analysis Methods for DC-to-DC Switching Converters", Proceedings of the International Semiconductor Power Converter Conference, March 1977, pp. 90111.

[7] F. Z. Peng, "Z-source inverter", IEEE Trans. Ind. Applicat., Vol. 39, No.2, Mar./Apr. 2003, pp.504-510.

[8] F. Z. Peng, M. Shen, and K. Holland, "Application of Z-Source Inverter for Traction Drive of Fuel Cell-Battery Hybrid Electric Vehicles", IEEE Transactions on Power Electronics, Vol. 22, No. 3, May 2007.

[9] F. Z. Peng, A. Joseph, J.Wang, M. Shen, "Z-Source Inverter for Motor Drives", IEEE Transactions on Power Electronics, Vol. 20, No. 4, July 2005.

[10] A. Das, D. Lahiri and A. K. Dhakar, "Residential Solar Power Systems using Z-Source Inverter", IEEE, pp. 1-6.

[11] J. Liu, J. Hu and L. Xu, "Dynamic Modeling and Analysis of Z Source Converter - Derivation of AC Small Signal Model and Design-Oriented Analysis", IEEE Transactions on Power Electronics, Vol. 22, No. 5, Sept. 2007, pp. 1786-1796.

[12] J. Liu, J. Hu and L. Xu, "A Modified Space Vector PWM for ZSource Inverter - Modeling and Design", 2005 International Conference on Electrical Machines and Systems, Nanjing, 2005, pp. 1242-1247 Vol. 2.

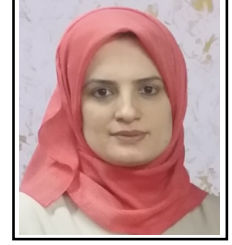

Lina J. Rashad was born in Baghdad, Iraq in May 7, 1983. She received the B.Sc., M.Sc. and Ph.D. degrees from University of Technology, Baghdad, Iraq, in 2006, 2008 and 2016 respectively.

In 2008, she joined the department of electrical engineering at university of technology, Baghdad, in Iraq, as an Asst. Lecturer. Currently she is a lecturer in the department of electrical engineering at university of technology, Baghdad, in Iraq. She has published over 15 refereed journal and conference papers in the areas of control systems, power electronics and electrical machine. 
